\title{
Bagaza virus and Plasmodium spp. coinfection in red-legged partridges ( Alectoris rufa ), in southern Spain 2019
}

Ursula Höfle $^{1}$, Teresa Cardona Cabrera ${ }^{1}$, Alberto Sánchez-Cano ${ }^{1}$, Isabel Fernandez de Mera $^{1}$, María A. Risalde ${ }^{2}$, Alberto Moraga Fernandez ${ }^{1}$, and José Antonio Ortiz ${ }^{3}$

${ }^{1}$ Instituto e Investigacion en Recursos Cinegeticos Grupo de Investigacion Sanidad y Biotecnologia

${ }^{2}$ Universidad de Cordoba Departamento de Anatomia y Anatomia Patologica Comparadas ${ }^{3}$ Grupo NETCO Medianilla sl Benalup Spain

January 5, 2022

\begin{abstract}
Flaviviruses West Nile (WNV), Usutu (USUV) and Bagaza (BAGV) virus and avian malaria parasites are vector borne pathogens that circulate naturally between avian and mosquito hosts. WNV and USUV and potentially also BAGV constitute zoonoses. Temporal and spatial co-circulation and co-infection with Plasmodium spp., and West Nile virus has been documented in birds and mosquito vectors, and fatally USUV infected passerines coinfected with Plasmodium spp. had more severe lesions. Also, WNV, USUV and BAGV have been found to co-circulate. Yet little is known about the interaction of BAGV and malaria parasites during consecutive or co-infections of avian hosts. Here we report mortality of free-living redlegged partridges in a hunting estate in Southern Spain due to coinfection with BAGV and Plasmodium spp. The outbreak occurred in the area where BAGV first emerged in Europe in 2010 and where co-circulation of BAGV, USUV and WNV was confirmed in 2011 and 2013. Partridges were found dead in early October 2019. Birds had mottled locally pale pectoral muscles, enlarged, congestive greenish-black tinged livers and enlarged kidneys. Microscopically congestion and predominantly mononuclear inflammatory infiltrates were evident and Plasmodium phanerozoites were present in the liver, spleen, kidneys, muscle and skin. Molecular testing and sequencing detected Plasmodium spp. and BAGV in different tissues of the partridges, and immunohistochemistry confirmed the presence and co-localization of both pathogens in the liver and spleen. Although Plasmodium spp. are known to be highly prevalent in red-legged partridges, this is the first account of mortality caused by co-infection with BAGV and Plasmodium sp. Due to the importance of the red-legged partridge in the ecosystem of the Iberian Peninsula and as driver of regional economy such mortalities are of concern. Also, they may reflect climate change related changes in host, vector and pathogen ecology and interactions that could emerge similarly in other pathogens.
\end{abstract}

\section{Running Title: BAGV/Plasmodiumcoinfection in partridges, Spain}

Bagaza virus and Plasmodium spp. coinfection in red-legged partridges (Alectoris rufa), in southern Spain 2019

Ursula Höfle ${ }^{1}$, Teresa Cardona Cabrera ${ }^{1}$, Alberto Sánchez-Cano ${ }^{1}$, Isabel G. Fernández de Mera $^{1}$, María A. Risalde ${ }^{2,3,4}$, Alberto Moraga-Fernández ${ }^{1}$, José Antonio Ortiz ${ }^{5}$ 
${ }^{1}$ Health and Biotechnology (SaBio) Research Group, National Wildlife Research Institute, Instituto de Investigación en Recursos Cinegéticos IREC (CSIC-UCLM), Ciudad Real, Spain

${ }^{2}$ Grupo de Investigación en Sanidad Animal y Zoonosis (GISAZ). Departamento de Anatomía y Anatomía Patológica Comparadas y Toxicología. Facultad de Veterinaria. Universidad de Córdoba (UCO), Córdoba, Spain

${ }^{3}$ Unidad de Enfermedades Infecciosas, Grupo de Virología Clínica y Zoonosis, Instituto Maimónides de Investigación Biomédica de Córdoba (IMIBIC), Hospital Reina Sofía, Universidad de Córdoba (UCO), Córdoba, Spain.

\section{${ }^{4}$ CIBERINFEC}

${ }^{\mathbf{5}}$ Grupo NETCO, Medianilla s.l., Benalup, Spain

\section{Summary (300 words)}

Flaviviruses West Nile (WNV), Usutu (USUV) and Bagaza (BAGV) virus and avian malaria parasites are vector borne pathogens that circulate naturally between avian and mosquito hosts. WNV and USUV and potentially also BAGV constitute zoonoses. Temporal and spatial co-circulation and co-infection with Plasmodium spp., and West Nile virus has been documented in birds and mosquito vectors, and fatally USUV infected passerines coinfected with Plasmodium spp. had more severe lesions. Also, WNV, USUV and BAGV have been found to co-circulate. Yet little is known about the interaction of BAGV and malaria parasites during consecutive or co-infections of avian hosts.

Here we report mortality of free-living red-legged partridges in a hunting estate in Southern Spain due to coinfection with BAGV andPlasmodium spp. The outbreak occurred in the area where BAGV first emerged in Europe in 2010 and where co-circulation of BAGV, USUV and WNV was confirmed in 2011 and 2013.

Partridges were found dead in early October 2019. Birds had mottled locally pale pectoral muscles, enlarged, congestive greenish-black tinged livers and enlarged kidneys. Microscopically congestion and predominantly mononuclear inflammatory infiltrates were evident andPlasmodium phanerozoites were present in the liver, spleen, kidneys, muscle and skin. Molecular testing and sequencing detectedPlasmodium spp. and BAGV in different tissues of the partridges, and immunohistochemistry confirmed the presence and co-localization of both pathogens in the liver and spleen. Although Plasmodium spp. are known to be highly prevalent in redlegged partridges, this is the first account of mortality caused by co-infection with BAGV andPlasmodium sp. Due to the importance of the red-legged partridge in the ecosystem of the Iberian Peninsula and as driver of regional economy such mortalities are of concern. Also, they may reflect climate change related changes in host, vector and pathogen ecology and interactions that could emerge similarly in other pathogens.

Keywords: Flavivirus; avian malaria; co-localization; avian host.

\section{Introduction}

Several emerging arboviruses including West Nile Virus (WNV), Zika virus and Bagaza virus (BAGV) have expanded their distribution over the past decade, causing major outbreaks in humans and/or animals (Benzarti et al., 2019; Pierson \& Diamond, 2020). BAGV is a flavivirus in the Ntaya serocomplex, closely related to Israel turkey meningoencephalomyelitis virus (ITV) (Fernández-Pinero et al. , 2014), first detected in a Culex mosquito pool in the Bagaza district of Central African Republic in 1966 (Digoutte., 1978). In 2010, BAGV emerged in Europe causing an outbreak in red-legged partridges (Alectoris rufa) and ringnecked pheasants (Phasianus colchicus ) (Agüero et al., 2011; Gamino et al., 2013) in Southern Spain and since has been shown to co-circulate with WNV and Usutu virus (USUV) (Llorente et al., 2013). In 2016 it caused an outbreak in Himalayan monal pheasants (Lophophorus impejanus ) in South Africa (Steyn et al., 2019) and it was detected in Culex genus mosquitoes in the United Arab Emirates in 2018 and Namibia in 2021 (Camp et al., 2019; Guggemos et al., 2021).

Although temporal and spatial co-circulation and coinfection of avian malaria parasites and WNV or USUV 
has been documented, both in birds and mosquito vectors (Hughes et al., 2010; Rouffaer et al., 2018), interaction of these Flaviviruses and malaria parasites during potential consecutive or coinfections of an avian host is not yet understood. Here we report a mortality event related to coinfection of red -legged partridges with Plasmodium spp. and BAGV.

\section{Material and methods}

In early October 2019, mortality of free-living red-legged partridges was detected in a hunting estate in Cádiz (Southern Spain). Partridges in fair to poor body condition were found dead, or with severe central nervous signs, similar to those observed in the BAGV-related mortality in the same geographic area in 2010. The birds showed weakness, ruffled feathers, apparent blindness and neurological signs such as ataxia that led to loss of flight coordination or complete inability to fly.

We carried out full, detailed post-mortem examination on four individual birds that had died after showing neurological signs or were found dead and collected vascular growing feathers, heart, brain, liver, spleen and kidney for pathogen detection in addition to a complete set of tissues (heart, brain, spleen, liver, kidney, lung, skeletal muscle, skin, cecal tonsils, adrenal glands, gonads and pancreas) for histopathology and immunohistochemistry. No ethical approval was required as this study was based on samples from deceased animals.

Whole DNA and RNA were manually extracted from pulp of growing feathers, heart, brain, liver, spleen and kidney using TRI Reagent@ (Merck Life Science, Madrid, Spain) according to manufacturer's instructions. We tested for the presence of haemosporidian parasites using a nested PCR with posterior sequencing of the 524 bp PCR product (Waldenström et al., 2004). Sample RNA was analyzed using a generic flavivirus SYBR Green (BioRad, Madrid, Spain) real-time reverse transcription PCR as described previously (Moureau et al., 2007) and the new obtained sequences were deposited in GenBank (acc. n. OK424741, OK424742). We used ClustalW to align the sequences of the NS5 gene fragment obtained in this study (highlighted in bold in Figure 2) and reference sequences from GenBank including different variants of Bagaza virus, from different localizations (partial segment, $222 \mathrm{bp}$ ). A total of 30 sequences were used for this analysis, and sequence of West Nile virus was used as an outgroup. A phylogenetic tree was generated using MEGA version 10 (http://www.megasoftware.net) (Kumar et al., 2018) with the Maximum Likelihood method with Kimura 2parameter distances (Kimura et al., 1980), this model was selected based on lowest values of Corrected Akaike Information Criterion (cAIC) and Bayesian Information Criterion (BIC). Reliability of internal branches was assessed using the bootstrapping method (1000 replicates).

In the case of avian malaria, phanerozoites observed in the hematoxilin-eosin-stained tissues were confirmed to be Plasmodiumspp. by immunohistochemistry (IHC) with the avidin-biotin-peroxidase complex (ABC) method (anti-Plasmodiumspp. polyclonal antibody; LSBio, Lifespan Biosciences, Seattle, Washington, USA). This method was also used to detect BAGV in different tissues, using a polyclonal anti-WNV antibody and following the protocol described by Gamino et al. (2013).

\section{Results}

All birds had enlarged congestive greenish-black tinged livers with a reticulate pattern, enlarged kidneys and mottled locally pale pectoral muscles (Figure 1A-C). The distribution, type and severity of lesions varied between animals. In all cases, the most prominent microscopic lesions were hyperemia and congestion, necrosis and mononuclear inflammatory infiltrates consisting of lymphoid cells, plasma cells and histiocytes, although to a different degree depending on the tissue. The liver showed congested central veins, an enlarged sinusoidal area, hemozoin pigment within hyperplastic Kupffer cells, and dense lymphoplasmacytic and histiocytic inflammatory cells within the portal tract and in perivascular spaces (Figure 1D). However, the most striking finding in the liver was the great number of phanerozoites inside hepatic cells (Figure 1D, inset). Other organs affected included the heart and, especially, the kidney, where multifocal necrosis along with mononuclear and polymorphonuclear infiltrates were the most important lesions (Figure 1E). Phanerozoites were also observed in other organs, especially in the skin and muscle where they were associated to multifocal necrosis as well as mononuclear and polymorphonuclear infiltrates (Figure $1 \mathrm{~F}$ ). In the spleen, lymphoid depletion, necrotic foci 
of lymphoid cells, multifocal granulocytic infiltrates and a severe hemosiderosis were evident. In the lung, oedema and congestion, as well as moderate to severe diffuse interstitial bronchopneumonia were observed. Lesions in the central nervous system were characterized by oedema, congestion, gliosis, neuronal necrosis, perivascular cuffing, capillary endothelial cell swelling, and perivascular infiltrates composed of mononuclear cells.

Using immunohistochemistry, BAGV antigen was detected in numerous organs, including spleen, liver, lung, kidney, central nervous system and muscle (Figure 1G, H). Specifically, antigen was detected in the cytoplasm of neurons and glial cells, endothelial and epithelial cells, macrophages and hepatocytes, often associated to necrotic foci (Figure 1H). Plamodium spp. phanerozoites observed in the hematoxilin-eosin stained tissues were confirmed to be Plasmodium spp. by immunohistochemistry (Figure 1I).

Bagaza virus was identified by real time RT-PCR and subsequent sequencing in vascular feather and brain samples of the partridges (Figure 2), while all tested tissues (feather, brain, spleen, heart, liver) also tested positive for Plasmodium spp.

\section{Discussion}

Here we describe interaction of Plasmodium and a Flavivirus in the recurrence of mortality little less than a decade after emergence of BAGV in red-legged partridges in Southern Spain. Flaviviruses andPlasmodium share the same mosquito vectors and coinfections of mosquitoes with Plasmodium and WNV have been described (Medeiros et al., 2016). Coinfections with Plasmodium have been detected in passerines from USUV related bird mortalities in the Netherlands and Belgium and USUV related lesions have recently been described to be more severe and mortality higher in passerines carrying malaria parasites (Giglia et al., 2020; Rijks et al., 2016; Rouffaer et al., 2018).This suggests that interactions between malaria parasites and Flaviviruses may influence the transmission dynamics and host pathogen interaction of these emerging pathogens (Hughes et al., 2010; Medeiros et al., 2014), but the relation and type of interactions between both pathogens in bird-feeding mosquitoes and in their avian hosts are unclear and information available to date is conflicting. In a study involving adult North American passerines coinfection withPlasmodium had a negative effect on WNV serostatus (Medeiros et al., 2014), while in a recent study in Spain WNV serostatus was not affected by concurrent Plasmodium infection (Ferraguti et al., 2021). A recent extensive study in Germany documented WNV and USUV coinfections but did not test for Plasmodium or other avian malaria parasites (Santos et al., 2021). As for vectors, mosquitoes infected with BAGV had reduced Japanese encephalitis (JEV) and WNV replication (Sudeep et al., 2015), but we are not aware of studies on concurrent infections with Plasmodium .

The BAGV sequences detected in this case differ from the BAGV detected in the first outbreak caused by this virus (Figure 2), while thePlasmodium sequences detected in the affected birds are identical and homologous to a sequence detected in biting midges and birds in the nearby Doñana National Park (Ferraguti et al., 2013). The detection of this particular genotype in midges, may be of interest, although we do not at this point have information on the importance of this fact. Also, previous studies on Plasmodium in red-legged partridges suggest that in a given population a number of Plasmodium lineages co-circulate and that Plasmodium prevalence as well as presence of generalist Plasmodium lineages may be influenced by releases of farmreared partridges (García et al., 2021). Avian malaria parasites are strictly vector bound and suspected to manipulate the biting behavior of their vectors in order to enhance transmission (Cornet et al., 2013), which could in the case of co-circulation in the same vector have an impact on transmission dynamics of locally circulating Flaviviruses such as BAGV. However, for BAGV in addition to mosquito-vector transmission, in red-legged partridges direct transmission has been demonstrated experimentally (Llorente et al., 2015), which suggests some degree of concurrent direct transmission at feeders in the case of highly managed populations in hunting estates.

While BAGV is pathogenic in red-legged partridges, avian malaria parasites are widespread and in Europe generally considered of little pathogenicity to avian hosts. However, especially Plasmodium spp. has led to local extinction of island endemic species when introduced with Eurasian birds to naïve populations and has 
also recently been suggested as one of the causes of the decline of abundant Eurasian birds such as the house sparrow (Passer domesticus ) (Dadam et al., 2019) and found associated to passerine mortalities in Austria (Dinhopl et al., 2015). Here mortality seemed to be mediated by the interaction of both pathogens. Potentially infection of previously Plasmodiuminfected partridges with BAGV and enhanced direct transmission due to aggregation at feeders and watering points could have led to the observed mortality. The ecoepidemiology and pathogenesis of this interaction in red-legged partridges and why this species seems to be especially susceptible, is unclear and needs further investigation.

Red-legged partridges are both a key species in Mediterranean ecosystems and, through the gamebird industry, an economic motor for depopulated regions in southern Spain (Caro et al., 2014; Casas et al., 2016). Mortality due to BAGV in the 2010 outbreak had a serious impact on the abundance of natural populations of the species and for the small game hunting sector (García-Bocanegra et al., 2013), thus reappearance of BAGV mediated mortality is of concern. More so as zoonotic potential of this virus has been discussed based upon detection of neutralizing antibodies against BAGV in patients with Meningoencephalitis in India (Bondre et al., 2009). Finally, this outbreak evidences the potential of interaction of co-circulating Plasmodium spp. and Flaviviruses, and as both groups harbor human pathogens the potential public health threat that such interaction could encompass should not be neglected.

\section{Acknowledgments}

This work was supported by the Instituto Nacional de Investigación y Tecnología Agraria y Alimentaria (INIA-CSIC) under grant E-RTA2017-00003-C02-02. We acknowledge the help of Francisca Talavera in preparation of histological slides.

\section{Conflict of Interest Statement}

The authors have declared no conflict of interest.

\section{Data availability statement}

All data generated or analyzed during the study are included in this published article. The datasets used and/or analyzed during the present research project are available from the corresponding author on reasonable request.

\section{Orcid}

Ursula Höfle:https://orcid.org/0000-0002-6868-079X

Teresa Cardona Cabrera:https://orcid.org/0000-0003-1568-0347

Alberto Sánchez-Cano:https://orcid.org/0000-0002-3521-5410

María A. Risalde:https://orcid.org/0000-0001-6751-1305

Isabel G. Fernández de Mera:https://orcid.org/0000-0001-5936-4018

Alberto Moraga-Fernández:https://orcid.org/0000-0002-6303-2937

\section{References}

Agüero, M., Fernández-Pinero, J., Buitrago, D., Sánchez, A., Elizalde, M., San Miguel, E., Villalba, R., Llorente, F., \& Jiménez-Clavero, M. A. (2011). Bagaza virus in partridges and pheasants, Spain, 2010.Emerging infectious diseases , 17, 1498-1501. https://doi.org/10.3201/eid1708.110077

Benzarti, E., Linden, A., Desmecht, D., \& Garigliany, M. (2019) Mosquito-borne epornitic flaviviruses: An update and review. TheJournal of general virology , 100, 119-132.https://doi.org/10.1099/jgv.0.001203

Bondre, V.P., Sapkal, G.N., Yergolkar, P.N., Fulmali, P.V., Sankararaman, V., Ayachit, V.M., Mishra, A.C., Gore, M.M. (2009). Genetic characterization of Bagaza virus (BAGV) isolated in India and evidence of 
anti-BAGV antibodies in sera collected from encephalitis patients. Journal General Virology . 90:2644-2649. doi:10.1099/vir.0.012336-0.

Camp, J. V., Karuvantevida, N., Chouhna, H., Safi, E., Shah, J. N. \& Nowotny, N. (2019). Mosquito biodiversity and mosquito-borne viruses in the United Arab Emirates. Parasites \& Vectors , 12, 153.https://doi.org/10.1186/s13071-019-3417-8

Caro, J., Delibes-Mateos, M., Vicente, J., Arroyo, B. (2014). A Quantitative Assessment of the Release of Farm-Reared Red-Legged Partridges (Alectoris rufa) for Shooting in Central Spain. European Journal Wildlife Research , 60, 919-926.https://doi.org/10.100\%\%2Fs10344-014-0861-9

Casas, F., Arroyo, B., Viñuela, J., Guzmán, J.L, Mougeot, F. (2016). Are farm-reared red-legged partridge releases increasing hunting pressure on wild breeding partridges in central Spain? European Journal Wildlife Research 62:79-84.https://doi.org/10.1007\%2Fs10344-015-0975-8

Cornet, S., Nicot, A., Rivero, A., \& Gandon, S. (2013). Malaria infection increases bird attractiveness to uninfected mosquitoes.Ecology Letters , 16, 323-329. https://doi.org/10.1111/ele.12041

Dadam, D., Robinson, R. A., Clements, A., Peach, W. J., Bennett, M., Rowcliffe, J.M., \& Cunningham, A. A. (2019). Avian malaria-mediated population decline of a widespread iconic bird species. Royal Society open science , 6, 182-197. https://doi.org/10.1098/rsos.182197

Digoutte, J. P. (1978). Bagaza (BAG) strain: Dak Ar B 209. The American journal of tropical medicine and hygiene, 27, 376-377. https://doi.org/10.4269/ajtmh.1978.27.376

Dinhopl, N., Nedorost, N., Mostegl, M. M., Weissenbacher-Lang, C., \& Weissenböck, H. (2015). In situ hybridization and sequence analysis reveal an association of Plasmodium spp. with mortalities in wild passerine birds in Austria. Parasitology Research , 114, 1455-1462. https://doi.org/10.1007/s00436-015-4328-z

Fernández-Pinero, J., Davidson, I., Elizalde, M., Perk, S., Khinich, Y., \& Jiménez-Clavero, M. A. (2014). Bagaza virus and Israel turkey meningoencephalomyelitis virus are a single virus species. The Journal of general virology , 95, 883-887. https://doi.org/10.1099/vir.0.061465-0

Ferraguti, M., Martínez-de la Puente, J., Ruiz, S., Soriguer, R., \& Figuerola, J. (2013). On the study of the transmission networks of blood parasites from SW Spain: diversity of avian haemosporidians in the biting midge Culicoides circumscriptus and wild birds. Parasites \& vectors , 6 , 208. https://doi.org/10.1186/1756$3305-6-208$

Ferraguti, M., Heesterbeek, H., Martínez-de la Puente, J., Jiménez-Clavero, M. Á., Vázquez, A., Ruiz, S., Llorente, F., Roiz, D., Vernooij, H., Soriguer, R., \& Figuerola, J. (2021). The role of different Culex mosquito species in the transmission of West Nile virus and avian malaria parasites in Mediterranean areas. Transboundary and emerging diseases , 68, 920-930. https://doi.org/10.1111/tbed.13760

Gamino, V., Gutiérrez-Guzmán, A. V., Fernández-de-Mera, I. G., Ortíz, J. A., Durán-Martín, M., de la Fuente, J., Gortázar, C., \& Höfle, U. (2012). Natural Bagaza virus infection in game birds in southern Spain. Veterinary research , 43, 65. https://doi.org/10.1186/1297-9716-43-65

García-Bocanegra, I., Zorrilla, I., Rodríguez, E., Rayas, E., Camacho, L., Redondo, I., Gómez-Guillamón, F. (2013). Monitoring of the Bagaza virus epidemic in wild bird species in Spain, 2010. Transboundary Emerging Diseases . 60(2):120-6. doi: 10.1111/j.1865-1682.2012.01324.x.

García, J. T., Viñuela, J., Calero-Riestra, M., Sánchez-Barbudo, I. S., Villanúa, D., \& Casas, F. (2021) Risk of Infection, Local Prevalence and Seasonal Changes in an Avian Malaria Community Associated with Game Bird Releases. Diversity , 13, 657. https://doi.org/10.3390/d13120657

Giglia, G., Reusken, C. B. E. M., Schaafsma, F., Mandara, M. T., Rijks, J., Sikkema, R., Gröne, A., Koopmans, M., Verheije, M. H., \& van den Brand, J. M. A. (2020). Usutu Virus Infection and PlasmodiumCo- 
Infection in Blackbirds (Turdus Merula ) in the Netherlands from 2016 to 2018. Journal of comparative pathology , 174, 155. https://doi.org/10.1016/j.jcpa.2019.10.044

Guggemos, H. D., Fendt, M., Hieke, C., Heyde, V., Mfune, J. K. E., Borgemeister, C., \& Junglen, S. (2021). Simultaneous circulation of two west nile virus lineage 2 clades and bagaza virus in the Zambezi region, Namibia. PLoS neglected tropical diseases , 15, e0009311. https://doi.org/10.1371/journal.pntd.0009311

Hughes, T., Irwin, P., Hofmeister, E., \& Paskewitz, S. M. (2010). Occurrence of avian Plasmodium and West Nile virus in Culex species in Wisconsin. Journal of the American Mosquito Control Association , 26 , 24-31. https://doi.org/10.2987/09-5893.1

Kimura, M. (1980). A simple method for estimating evolutionary rate of base substitutions through comparative studies of nucleotide sequences. Journal of molecular evolution , 16, 111-120. https://doi.org/10.1007/BF01731581

Kumar, S., Stecher, G., Li, M., Knyaz, C., \& Tamura, K. (2018). 'MEGA X: Molecular Evolutionary Genetics Analysis across Computing Platforms',Molecular biology and evolution , 35, 1547-1549. https://doi.org/10.1093/molbev/msy096

Llorente, F., Pérez-Ramírez, E., Fernández-Pinero, J., Soriguer, R., Figuerola, J., \& Jiménez-Clavero, M. Á. (2013). Flaviviruses in Game Birds, Southern Spain, 2011-2012. Emerging infectious diseases , 19, 1023-1025. https://doi.org/10.3201/eid1906.130122

Llorente, F., Pérez-Ramírez, E., Fernández-Pinero, J., Elizalde, M., Figuerola, J., Soriguer, R. C., \& JiménezClavero, M. Á. (2015). Bagaza virus is pathogenic and transmitted by direct contact in experimentally infected partridges, but is not infectious in house sparrows and adult mice. Veterinary research , 46, 93. https://doi.org/10.1186/s13567-015-0233-9

Medeiros, M. C., Anderson, T. K., Higashiguchi, J. M., Kitron, U. D., Walker, E. D., Brawn, J. D., Krebs, B. L., Ruiz, M. O., Goldberg, T. L., Ricklefs, R. E., \& Hamer, G. L. (2014). An inverse association between West Nile virus serostatus and avian malaria infection status.Parasites 83 vectors , 7, 415. https://doi.org/10.1186/1756-3305-7-415

Medeiros, M. C., Ricklefs, R. E., Brawn, J. D., Ruiz, M. O., Goldberg, T. L., \& Hamer, G. L. (2016). Overlap in the Seasonal Infection Patterns of Avian Malaria Parasites and West Nile Virus in Vectors and Hosts. The American journal of tropical medicine and hygiene , 95, 1121-1129. https://doi.org/10.4269/ajtmh.16-0236

Moureau, G., Temmam, S., Gonzalez, J. P., Charrel, R. N., Grard, G., \& de Lamballerie, X. (2007). A real-time RT-PCR method for the universal detection and identification of flaviviruses. Vector borne and zoonotic diseases (Larchmont, N.Y.), 7, 467-477. https://doi.org/10.1089/vbz.2007.0206

Pierson, T. C., \& Diamond, M. S. (2020). The continued threat of emerging flaviviruses. Nature microbiology , 5, 796-812. https://doi.org/10.1038/s41564-020-0714-0

Rijks, J. M., Kik, M. L., Slaterus, R., Foppen, R., Stroo, A., IJzer, J., Stahl, J., Gröne, A., Koopmans, M., van der Jeugd, H. P., \& Reusken, C. (2016). Widespread Usutu virus outbreak in birds in the Netherlands, 2016. Euro surveillance: bulletin Europeen sur les maladies transmissibles $=$ European communicable disease bulletin , 21, 30391. https://doi.org/10.2807/1560-7917.ES.2016.21.45.30391

Rouffaer, L. O., Steensels, M., Verlinden, M., Vervaeke, M., Boonyarittichaikij, R., Martel, A., \& Lambrecht, B. (2018). Usutu Virus Epizootic and Plasmodium Coinfection in Eurasian Blackbirds (Turdus merula) in Flanders, Belgium. Journal of wildlife diseases , 54, 859-862. https://doi.org/10.7589/2017-07-163

Santos, P. D., Michel, F., Wylezich, C., Höper, D., Keller, M., Holicki, C. M., Szentiks, C. A., Eiden, M., Muluneh, A., Neubauer-Juric, A., Thalheim, S., Globig, A., Beer, M., Groschup, M. H., \& Ziegler, U. (2021) Co-infections: Simultaneous detections of West Nile virus and Usutu virus in birds from Germany. Transboundary emerging diseases . 00, 1- 17. https://doi.org/10.1111/tbed.14050 
Steyn, J., Botha, E. M., Lourens, C., Coetzer, J. A. W., \& Venter, M. (2019). Bagaza Virus in Himalayan Monal Pheasants, South Africa, 2016-2017. Emerging infectious diseases , 25, 2299-2302. https://doi.org/10.3201/eid2512.190756

Sudeep, A. B., Bondre, V. P., George, R., Ghodke, Y. S., Aher, R. V., \& Gokhale, M. D. (2015). Bagaza virus inhibits Japanese encephalitis \& West Nile virus replication in Culex tritaeniorhynchus \&Cx. quinquefasciatus mosquitoes. The Indian journal of medical research, 142, S44-51. https://doi.org/10.4103/0971-5916.176618

Waldenström, J., Bensch, S., Hasselquist, D., \& Ostman, O. (2004). A new nested polymerase chain reaction method very efficient in detecting Plasmodium and Haemoproteus infections from avian blood. The Journal of parasitology , 90, 191-194. https://doi.org/10.1645/GE-3221RN

Figure legends

Figure 1. Lesions and antigen distribution of Bagaza virus (BAGV) and Plasmodium spp. in partridges. A) Liver of greenish-black color presenting hepatomegaly. B) Pale kidneys with nephromegaly. C) Paleness of pectoral muscles. D) Perivascular and parenchymal infiltrate of lymphoplasmacytic and histiocytic inflammatory cells in liver (light grey arrows), associated to abundant phanerozoites inside hepatic cells and sinusoids (inset, light grey arrowheads). E) Severe necrosis and lymphoplasmacytic and histiocytic infiltrates in renal tubules and glomeruli $(*)$. F) Pectoral muscle presenting necrotic foci along with mononuclear and polymorphonuclear infiltrated cells $\left(^{*}\right)$ and degeneration of muscular fibers (black arrows). G) Kupffer cells and hepatocytes in the liver positive to BAGV by immunohistochemistry (black arrowheads). H) Macrophages, lymphocytes and tubular epithelial cells inside a necrotic focus in the kidney showing BAGV immunolabeling (black arrowheads). I) Immunopositive phanerozoites of Plasmodium spp. in necrotic and inflammatory cells present in pectoral muscle (gray arrowheads).

Figure 2 . Phylogenetic tree based on NS5 fragment sequences of Bagaza virus identified in red-legged partridges in the present study (marked with circles) compared with other related sequences from different countries.

Figure 1.

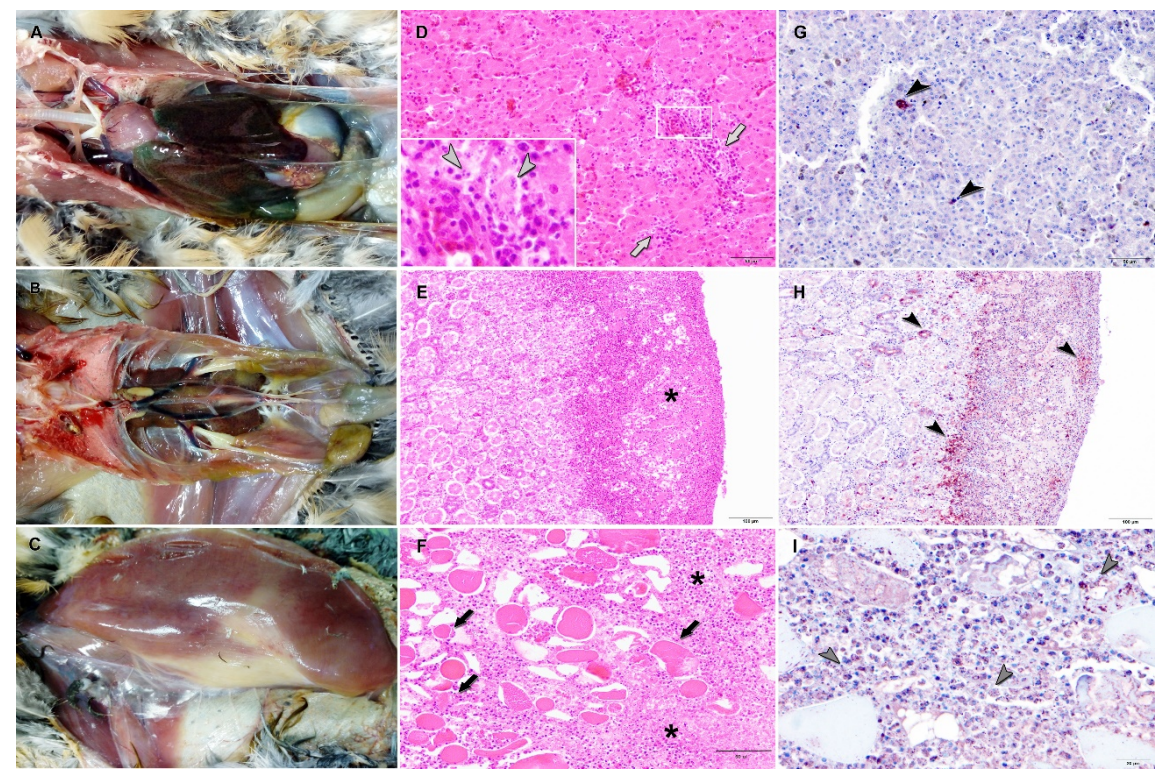




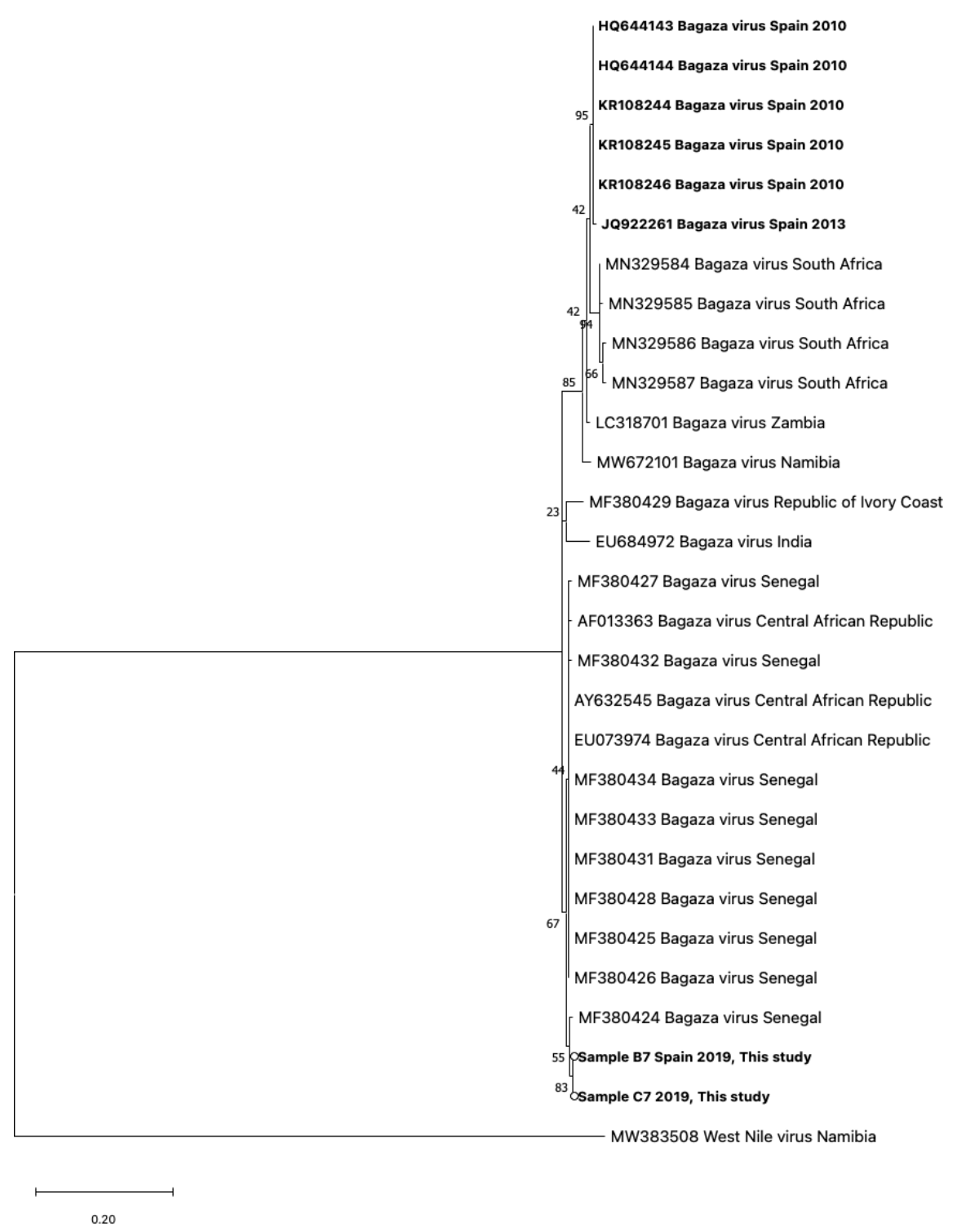

Figure 2. 